\title{
Komodifikasi Budaya dalam Konstruksi Realitas Media Massa
}

\author{
WIDODO MUKTIYO \\ Fakultas Ilmu Sosial dan Ilmu Politik, Universitas Sebelas Maret Surakarta, \\ Email: muktiyo@yahoo.com
}

\begin{abstract}
Culture is an inseparable component of mass media coverage. Unfortunately, mass media portrays culture in various forms, from culture as a part of community values to culture as a commodification of business media. This study was conducted to explore the process of commodification of culture in both local and national media that can be observed in two cultural centers of the nation, Bali and Solo. This study used qualitative research method. Data was collected from interviews and a study of documents of news about culture in local media (the Bali Post and the Solo Post). The data from both regions were subsequently compared. The results of this study conclude that cultural commodification is constructed in local, regional, and national media.
\end{abstract}

Keywords: local culture, commodification, mass media

\begin{abstract}
Abstrak. Budaya telah menjadi bagian dalam pemberitaan media massa yang tidak dapat dipisahkan. Namun demikian, realitas budaya di dalam media massa telah terkonstruksi secara beranekaragam, mulai dari budaya sebagai nilai-nilai masyarakat sampai budaya sebagai komodifikasi bisnis media. Kajian ini berusaha mengupas proses komodifikasi budaya pada media lokal dan nasional di daerah-daerah yang menjadi pusat budaya, yaitu Bali dan Surakarta. Metode penelitian deskriptif kualitatif digunakan dalam penelitian ini, berdasarkan wawancara dan studi dokumen pemberitaan budaya di media lokal (Bali Post di Bali dan Solopos di Solo) dan media regional dan nasional (Radar Bali / Jawa Post di Bali dan Kedaulatan Rakyat di Solo). Melalui analisis perbandingan rubrikasi media khususnya pemberitaan kolom utama dan kolom khusus tentang pemberitaan kebudayaan di Bali dan Solo, hasil penelitian menunjukkan konsistensi bahwa semua media melakukan komodifikasi budaya dalam penyajian informasi yang berkaitan dengan budaya lokal di Bali dan Solo.
\end{abstract}

Kata kunci: budaya lokal, komodifikasi, media massa

\section{Pendahuluan}

Konstruksi kultural oleh media massa sudah menjadi perhatian ilmu komunikasi sejak beberapa waktu lalu. Pandangan Peter D. Moss (1999) dalam buku Eriyanto; Analisis Framing: Konstruksi, Ideologi dan Politik Media disebutkan bahwa ketika berwacana maka media telah melakukan konstruksi kultural, dengan membingkai fakta dalam kerangka tertentu menjadi produk informasi. Konstruksi kultural ini merupakan serangkaian proses konstruksi realitas yang ditangkap, dikemas dan disebarkan oleh media melalui politik pemaknaan dan bahasa (Eriyanto, 2002).

Kajian terhadap realitas produk media yang berhubungan dengan nilai-nilai budaya lokalnya masih kurang dikaji, terutama dalam kaitannya dengan proses komodifikasi yang demikian kuat dalam arus globalisasi dan kapitalisme media. Kondisi ini juga terkait dengan penilaian Chaerowati et al. (2013: 145) tentang kecenderungan media mainstream lebih banyak menomorsatukan peristiwa-peristiwa berskala besar dan nasional dari pada potret sosial masyarakat yang bersifat lokalitis.

Sebagai respons terhadap pandangan Chaerowati di atas, kajian ini mengamati bagaimana media lokal, regional, dan nasional mengangkat budaya lokal sebagai modal pemberitaannya. Hal yang dipertanyakan terkait apa saja produk nilai-nilai budaya lokal yang terpampang dalam media

Received: 7 Desember 2014, Revision: 19 Mei 2015, Accepted: 23 Mei 2015

Print ISSN: 0215-8175; Online ISSN: 2303-2499. Copyright@2015. Published by Pusat Penerbitan Universitas (P2U) LPPM Unisba Terakreditasi SK Kemendikbud, No.040/P/2014, berlaku 18-02-2014 s.d 18-02-2019 
tersebut sebagai hasil dari pergulatan dalam manajemen media, baik terhadap kepentingan pemilik medianya maupun dengan para profesional media. Dalam konteks seperti ini, adalah relevan untuk memertanyakan juga kesimpulan Pawito (2013: 113) yang menyatakan bahwa fungsi media massa salah satunya adalah untuk memroduksi dan mereproduksi identitas budaya.

Kajian ini berfokus pada upaya memberikan deskripsi mengenai dinamika media dalam memroduksi, mengemas dan menyajikan isu-isu budaya lokal sebagai sebuah produk media yang layak dikonsumsi dalam sebuah industri media koran lokal, regional dan nasional yang dihadapkan pada kondisi globalisasi. Di samping itu, melihat dalam format apa saja nilai-nilai budaya Bali sebagai budaya lokal mampu direkonstruksi di media massa menjadi sebuah komoditas dalam situasi globalisasi dan kapitalisme yang berjalan demikian kuat di era reformasi.

Penelitian ini menggunakan metode deskriptif kualitatif. Subjek dalam penelitian ini adalah rubrikasi lokal media cetak Bali Post, Radar Bali, Solopos dan Kedaulatan Rakyat, dengan pertimbangan bahwa mediamedia tersebut merupakan pemain besar media harian di Bali dan Surakarta yang memiliki oplah cukup tinggi. Sumber informasi penelitian ini terdiri atas beberapa pihak yang terkait dengan kebutuhan penelusuran konsepkonsep dasar penelitian komodifikasi kultural dalam konstruksi media massa, diantaranya adalah jurnalis media sebagai pelaku media lokal, tokoh adat atau budayawan sebagai pelestari budaya lokal dan akademisi sebagai pengamat media dan budaya lokal.

Analisis dalam penelitian ini adalah perbandingan yaitu membandingkan komodifikasi melalui rubrikasi lokal baik dalam kolom utama maupun kolom khusus pada media cetak di Bali dengan Surakarta. Kedua daerah dipilih berdasarkan pertimbangan sebagai pusat kebudayaan Bali dan Jawa.

\section{Ekonomi Politik Media}

Pandangan umum ekonomi politik media mengarah pada pengembangan nilainilai kapitalis yang mulai merasuk ke seluruh sendi kehidupan. Aliran ataupun mazhab kapitalistik menjadi alternatif yang mesti di piih masyarakat, sehingga bangunan ataupun struktur termasuk di dalamnya para profesional media mengikuti sistem nilai tersebut.

Tinjauan ekonomi politik merupakan studi tentang hubungan-hubungan sosial, khususnya hubungan kekuasaan yang secara bersama-sama membentuk atau memengaruhi produksi, distribusi dan konsumsi sumber daya (Mosco, 1996: 25). Dalam bidang komunikasi sumber daya yang dimaksud adalah media itu sendiri bersama dengan khalayaknya. Interaksi antara media dan khalayaknya senantiasa didasarkan atas kepentingan yang bersifat politis dan berada dalam arus yang tarik menarik.

Sistem politik menekankan hubungan dengan manajemen kekuasaaan dan alat kontrol dalam kehidupan masyarakat dan memberi corak pada wujud organisasi medianya. Sedangkan sistem ekonomi lebih berhubungan dengan pengaturan dan penataan terhadap proses produksi, distribusi, dan konsumsi sumber daya ekonomi dan sosial manusia demi keberlangsungan kehidupannya yang lebih manusiawi (Mosco, 1996: 26).

Mosco (1996) secara khusus juga menjelaskan dalam mengamati realitas media sebagai institusi sosial sekaligus institusi bisnis dihadapkan pada tiga konsep dasar yaitu komodifikasi, spasialisasi dan strukturasi. Komodifikasi mengacu pada proses transformasi nilai guna, nilai yang didasarkan pada kemampuan dalam memenuhi kebutuhan terhadap suatu nilai tukar yang didasarkan pada kepentingan pasar. Komodifikasi ini menjadi penting dalam komunikasi karena prosesnya akan memberikan sumbangan dalam proses komodifikasi ekonomi secara keseluruhan.

Dalam praktik, komodifikasi dapat mencakup dalam tiga kategori, yaitu: komodifikasi isi, komodifikasi khalayak dan komodifikasi cybernetic. Komodifikasi isi merupakan proses mengubah pesan dari sekumpulan data ke dalam sistem makna yang kemudian dapat dipasarkan. Berbagai exposure terhadap nilai-nilai lokal budaya Bali dan Jawa di dalam koran lokal sebagai manifestasi dan aktualisasi dari nilai-nilai lokal tersebut dapat dipahami sebagai sebuah proses komodifikasi yang sangat strategis. Proses olahan dalam ruang redaksi akan berjalan demikian dinamis dalam berbagai pertimbangan antara struktur dan agensi. Representasi isi yang muncul tersebut pada akhirnya menjadi exposure yang telah mengalami proses komodifikasi.

Komodifikasi khalayak memiliki makna bahwa media mampu menghasilkan sebuah proses yang memungkinkan media menjajakan 
sejumlah khalayak sebagai konsumen. Media hadir dalam kerangka hubungan dengan pihak lain yaitu pembacanya. Realitas isi yang hadir menjadi sebuah komodifikasi yang senantiasa direlasikan dengan kepentingan institusi bisnis lainnya seperti pengiklan, biro iklan atau pihak-pihak yang ingin menjadikan media sebagai wahana "tampil" yang efektif. Komodifikasi khalayak menjadi bagian integral dari komodifikasi isi dalam menopang survival institusi media.

Dalam praktik terhadap nilai-nilai budaya setempat maka relasi itu akan saling menguatkan terhadap isi yang hendak dibangunnya, sehingga keterlibatan khalayak menjadi perlu dipertimbangkan secara mutualistik. Komodifikasi khalayak mengagregasikan berbagai unsur dalam sebuah kepentingan yang lebih utama yaitu keuntungan bagi medianya, oleh karena proses tersebut menjadikan media berada dalam tujuan utama dalam hal keuntungan kapitalnya.

Dalam komodifikasi cybernetic dibagi meliputi komodifikasi intrinsik dan ekstrinsik. Komodifikasi intrinsik adalah tinjauan layanan jasa rating khalayak oleh media, sehingga yang dipertukarkan bukan pesan atau khalayak akan tetapi nilai rating yang dihasilkan. Berbagai lembaga riset media meneliti, mengolah dan menjual hasil kajian yang menyangkut rating tersebut sebagai sebuah komoditas yang diperlukan media agar senantiasa berada dalam tampilan yang optimal di mata khalayaknya. Dalam media penyiaran seperti TV, proses ini banyak ditempuh sehingga kepentingan rating sebagai panglima bagi pengelola media. Namun, dalam media cetak rating juga tetap dipertimbangkan sebagai hasil survei seperti SRI atau media scene menjadi acuan penting dalam penentuan ragam isi di masa yang akan datang.

Komodifikasi ekstrinsik merupakan proses komodifikasi yang menjangkau seluruh kelembagaan pendidikan, informasi pemerintah, media dan budaya yang diharapkan menjadi pendorong bagi khalayak sehingga tidak semua orang dapat mengakses produk media. Dengan demikian, komodifikasi cybernetic menjadikan media sebagai sebuah ajang adu prestasi yang dinilai publik. Media menjadi representasi persepsi publik dimana diversitas isi didasarkan atas adanya selera dan penilaian publik akan senantiasa menjadi parameter keberhasilannya mengelola media.

Pisau analisis perspektif ekonomi politik media yang lainnya berupa spasialisasi. Spasialisasi merupakan konsep yang membicarakan tentang proses dalam rangka menanggulangi berbagai hambatan dalam persoalan ruang dan waktu di dalam kehidupan sosial. Mosco menyebutkan adanya konsentrasi terhadap spasialisasi yang horizontal, vertikal dan transnasional.

Spasialisasi horizontal dalam bisnis media berkenaan dengan realitas kepemilikan yang bersifat silang terhadap institusi media. Sebuah korporasi media tidak berdiri dalam satu jenis media, namun berwujud dalam jaringan mata rantai yang saling menunjang. Wujud ini menjadikan media sebagai sebuah bisnis yang terintegrasi dan bersifat konglomerasi. Keberadaan kelompok KKG (Kelompok Kompas Gramedia) yang memiliki harian Kompas, Radio Sonora, Global $T V$ dan berbagai media lainnya. Atau Grup Jawa Pos yang memiliki 107 koran lokal di berbagai daerah dan juga TV Lokal. Upaya konglomerasi media dan nafsu memiliki semua jenis media menjadi indikator dalam pengkajian spasialisasi horizontal.

Sedangkan spasialisasi yang bersifat vertikal adalah upaya penguasaan dari hulu sampai hilir oleh pemilik media. Seperti kelompok usaha Subentra yang menguasai jaringan usaha importir film, sekaligus memiliki jaringan bioskop di seluruh Indonesia, yaitu Bioskop 21 dan entah apalagi nantinya agar struktur organisasi bisnisnya makin kuat. Yang terakhir adalah spasialisasi, yang bersifat transnasional di mana usaha terhadap penguasaan media yang menjangkau lintas negara yang juga menjadi sebuah fenomena baru, baik keterlibatannya secara langsung maupun tidak langsung sehingga tarikan kapital asing terhadap daya beli konsumen lokal akan sangat kentara dan dapat merugikan kepentingan media lokal.

Strategi media dalam mengemas produknya terhadap konten lokal (nilai-nilai budaya lokal) menjadi komoditas baru yang barangkali punya relung yang terbuka dan penuh tantangan. Bilamana dikemas tidak seperti isu-isu yang bersifat global akan dapat memberikan keragaman terhadap nilai-nilai lokal yang pada akhirnya dapat memberikan nilai tambah yang baru yang menguntungkan media.

Perspektif yang ketiga adalah strukturasi yang merupakan proses di mana struktur yang ada dibangun oleh agensi. Kehidupan sosial maupun kehidupan media yang telah ada, bukan lahir dengan sendirinya, namun 
terjadi hasil interaksi antara struktur dengan agensi. Di dalam proses perubahan sosial terlihat jelas adanya proses struktur yang diproduksi dan direproduksi oleh agensi yang bertindak melalui medium struktur. Proses strukturasi akan mampu mengonstruksi adanya hegemoni, apalagi dalam kerangka media sebagai media ekonomi.

Profesional media dalam ruang redaksi selalu bekerja untuk melakukan proses terhadap berbagai liputan dengan berbagai pertimbangan dan orientasi penentuan yang dipilih secara beragam. Pemilihan sudut pandang tertentu terhadap sebuah corak dan ragam exposure isi sepertinya dibimbing oleh skemata tata aturan (kaidah) yang dinyatakan bahwa isi media itu selalu bersifat marketable atau yang sesuai dengan tuntutan dan selera pasar. Inilah prinsip pasar dalam koridor kapitalisme yang akan lahir dalam praktik media, sehingga skemata tersebut akhirnya menjadi sebuah aturan (rules). Dalam berbagai situasi aturan tersebut dapat berupa rambu-rambu atau konvensi yang tidak tertulis tetapi harus ditaati oleh anggotanya.

Hubungan antara kepentingan pemilik modal (owner), orientasi, dan komitmen profesional media, serta kepedulian kalangan publik seperti para budayawan, akademisi dan lain-lain senantiasa memberikan wujud tampilan yang bisa terpetakan. Peta persuratkabaran, khususnya lokal menjadi makin beragam dan bersifat lokal (locally) sehingga berbagai upaya dalam menunjukkan eksistensi sebagai industri yang wilayah pasarnya terbatas terus dicarikan bentuk yang dapat menghasilkan produk yang menguntungkan, baik dari sisi bisnis medianya maupun pemenuhan kebutuhan dan keinginan khalayaknya.

\section{Budaya Bali dan Budaya Jawa sebagai Budaya Lokal}

Yang dimaksud budaya lokal dalam kajian ini adalah:

".... budaya yang berkembang di suatu daerah,
yang unsur-unsurnya adalah budaya suku-
suku bangsa yang tinggal di daerah itu, yang
kenyataannya kebudayaan daerah ini diwarnai
oleh budaya suatu suku bangsa tertentu yang
dominan di daerah tersebut (Rumusan Temu
Budaya Surabaya, 24 Juni 2002).

Budaya lokal adalah budaya dari unit-unit sosial (kelompok sosial, lapangan sosial, golongan sosial, suku bangsa) yang ada di suatu daerah, yang dijadikan acuan warga masyarakat untuk saling berinteraksi"(Rumusan Temu Budaya
Yogyakarta, 5-6 Agustus 2002). Dari rumusan tsb budaya lokal merupakan hasil cipta budaya dari suatu daerah yang melingkupi segenap unsur pembentuk budaya di suatu daerah tertentu. Budaya Bali dan Jawa di Indonesia menjadi suatu point of interest dari rumusan di atas, sehingga urgensi kajian ini terhadap nilai-nilai budaya Bali dan Jawa di media koran menjadi keunikan tersendiri.

Budaya bersifat dinamis, termasuk pula budaya lokal. Budaya lokal yang menjadi khazanah bagi masyarakat suku tertentu, telah memunculkan unsur-unsur dalam budaya lokal dapat berupa beragam produk budaya, tata nilai dan keyakinan, yang memunculkan local wisdom dan pranata sosial tertentu. Berbagai kaidah dasar kehidupan dan falsafah dalam budaya Bali dan Jawa senantiasa menjadi sebuah realitas tersendiri yang dapat berwujud secara materi seperti berbagai bentuk kesenian maupun yang bersifat nonmateri yang tercermin dalam sikap dan perilaku. Realitas sosial ini menjadi sesuatu yang penting dan dipentingkan oleh komunitasnya sehingga kepedulian media dalam merekonstruksi adalah hal yang menarik. Proses selektivitas realitas sosial yang sarat dengan nilai-nilai lokal tersebut ke dalam media dapat menjadi sarana penemuan jatidiri para pembacanya yang senantiasa berada dalam proses identifikasi nilai-nilai kulturalnya.

\section{Media Lokal}

Setiap orang sulit menemukan suatu batasan yang terbaru, konsisten dan dapat diterima di mana-mana tentang media. Setiap media memiliki beberapa reputasi tertentu yang bentuk dan fungsinya seringkali bervariasi (McQuail, 1991: 8). Dalam sejarah media massa, terdapat empat unsur utama dalam penggolongan pola acuan Eropa Barat yaitu: (1) Teknologis; (2) Situasi Politik, Sosial dan Masyarakat; (3) Serangkaian tergantung fungsi dan kebutuhan; (4)Sisi manusia dalam arti kelompok, Sosial dan Kelompok berkepentingan. Sementara itu, media cetak dalam bentuk koran secara geografis terbagi dalam klasifikasi koran nasional, regional, ataupun bentuk lokal.

Media seringkali dipandang sebagai sarana pengembangan kebudayaan yang bukan saja dalam artian pengembangan bentuk seni dan simbol, akan tetapi juga dalam pengertian pengembangan tata cara, mode, gaya hidup dan norma-norma. Media terasa telah menjadi sumber dominan untuk 
memeroleh gambaran dan citra realitas sosial bagi individu dan masyarakat secara kolektif yang dikemas dalam bentuk berita sekaligus punya nilai hiburan (McQuail, 1991: 3).

Media lokal dalam wujud koran lokal hadir dalam jumlah yang tidak terbatas semenjak dibukanya kran reformasi, yang justru sangat kuat terjadi di daerah. Terutama respons elit para masyarakat yang hendak memiliki media lokalnya yang demikian mudah. Keuntungan diberikan koran lokal di daerah menyajikan realitas lokal menjadi sebuah wacana untuk diolah atau diproduksi sebagai bahan informasi yang dibutuhkan masyarakatnya. Koran lokal menjadi bahan kajian yang dinamis dalam tatanan otonomi daerah yang merasuk dalam semua sisi kehidupan di daerah, interaksi antarmedia dengan nilai-nilai lokal sebagai entitas lokal terungkap dalam proses produksi dan distribusi media lokal.

Sementara itu, media yang dijadikan pusat kajian ini adalah pers yang terbit dan eksis di daerah Bali yakni; Harian Umum Bali Post dan Harian Umum Radar Bali. Bali Post dipilih berdasarkan jumlah oplah yang tertinggi di Bali. Harian Bali Post merupakan salah satu anak perusahaan dari Kelompok Media Bali Post yang diterbitkan oleh PT Bali Post. Selain menerbitkan Bali Post, Kelompok Media Bali Post juga mengelola Harian BisnisBali, Harian Denpasar Post, Mingguan Bali Travel News, Mingguan Tokoh, Dwi Mingguan Wiyata Mandala, Dwi Mingguan Lintang, dan harian Suara NTB yang terbit di Mataram, Nusa Tenggara Barat.

Di bidang media elektronik, Kelompok Media Bali Post juga mengelola Radio Global Kini Jani, Radio Suara Besakih, Radio Genta FM, Radio Singaraja FM, Radio Suara Banyuwangi, RadioLombok FM dan Radio Negara FM. Dalam bidang pertelevisian, lembaga tersebut mengembangkan stasiun BaliTV, BandungTV, JogyaTV, SemarangTV, MedanTV, Aceh TV, Sriwijaya TV, Makasar TV dan Surabaya TV.

Koran kedua yang dipilih adalah Radar Bali. Lahirnya harian Radar Bali tidak bisa dipisahkan dari mengguritanya koranJawa Pos di berbagai daerah di Indonesia. Sejak adanya Undang-Undang (UU) Pokok Pers dan UU Otonomi Daerah, Jawa Pos memang makin intensif mendirikan koran di berbagai daerah, termasuk Bali. Menyusul keberhasilan mendirikan koran bernama Radar di berbagai kota di Jawa Timur, Jawa Pos pun mengembangkan Radar ke Jawa Tengah, Jawa Barat, Bali, Lampung, Medan, hingga Papua.
Menggunakan bendera PT Bali Intermedia Pers, Jawa Pos pun menerbitkan koran lokal Bali bernama Radar Bali. Radar Bali terbit pertama kali pada 12 Februari 2001 dalam bentuk koran suplemen Jawa Pos. Hingga saat ini PT Bali Intermedia Pers tidak menerbit media lain selain Radar Bali. Namun, mereka punya percetakan PT Temprina yang juga jadi tempat cetak koran lain yaitu NusaBali dan Fajar Bali (Muhajir, 2011).

Selanjutnya, hasil penelitian media cetak di Bali dibandingkan dengan media cetak di Surakarta. Media yang menjadi kajian adalah Harian Umum Kedaulatan Rakyat dan Harian Umum Solopos. Kedaulatan Rakyat dipilih karena mempunyai keterkaitan yang sangat erat dalam berbagai sejarah panjang perjuangan bangsa dan sebagai pers perintis kemerdekaan hingga zaman reformasi ,dan ternyata tetap terbukti eksis hingga saat ini, yang beredar di wilayah Mataram kuno atau Yogyakarta dan sekitarnya. Sedangkan Solopos, meskipun tergolong koran baru (lahir hampir bersamaan dengan kelahiran era reformasi tahun 1997) di Surakarta, namun demikian Solopos telah menjadi representasi koran lokal di Solo yang sehat, profesional dan berkembang secara baik. Sebagai bagian dari jaringan bisnis koran nasional yaitu Bisnis Indonesia, maka Solopos sebagai koran lokal di pusat budaya Jawa punya spesifikasi yang khas oleh karena kuatnya nilai budaya masyarakat khalayaknya. Solopos berada dalam arus globalisasi yang sangat erat karena sebagai bagian dari koran nasional (Widodo, 2014).

Pemilihan media-media tersebut juga didasari oleh adanya kebijakan redaksional dari kedua koran tersebut yang masih memberi space (ruang berita) yang cukup memadai dan kreatif untuk isu-isu nilai-nilai lokal, yaitu budaya Jawa dan Bali. Proses elaborasi terhadap realitas lokal tersebut ditangkap dan dimaknai dalam frame media yang khas. Media tersebut tidak sekadar sebagai cerminan dari kapitalisme global namun sarat dengan wacana lokal yang dikemas secara khusus, sehingga punya nilai komoditas yang justru banyak diminati oleh pembacanya.

\section{Analisis Komodifikasi Kultural}

\section{(1) Terpaan (Eksposure) dan Komodifikasi Harian Bali Post}

Harian Bali Post setiap minggunya memiliki rubrik khusus berbahasa Bali yang terbit pada hari Minggu. 
Tabel 1

Profil Harian Umum di Bali dan Surakarta

\begin{tabular}{|c|c|c|c|c|}
\hline \multirow[b]{2}{*}{ Kriteria } & \multicolumn{2}{|c|}{ Media Lokal } & \multicolumn{2}{|c|}{ Media Regional-Nasional } \\
\hline & Bali Post & Solopos & $\begin{array}{l}\text { Radar Bali } \\
\text { (Jawa Pos) }\end{array}$ & $\begin{array}{c}\text { Kedaulatan } \\
\text { Rakyat }\end{array}$ \\
\hline $\begin{array}{l}\text { Kepemilikan } \\
\text { Media }\end{array}$ & $\begin{array}{l}\text { Kepemilikan keluarga } \\
\text { Ketut Nadha dan } \\
\text { keluarga Satria Naradha }\end{array}$ & $\begin{array}{l}\text { Kepemilikan } \\
\text { Umum } \\
\text { H.Soekamdani } \\
\text { pemegang saham } \\
\text { mayoritas }\end{array}$ & $\begin{array}{l}\text { Kepemilikan } \\
\text { umum Eric F.H } \\
\text { Samola (Jawa } \\
\text { Pos) }\end{array}$ & $\begin{array}{l}\text { Kepemilikan } \\
\text { KeluargaH. } \\
\text { Semawai dan } \\
\text { M.Wonohito }\end{array}$ \\
\hline $\begin{array}{l}\text { Latar } \\
\text { Belakang } \\
\text { Pendirian } \\
\end{array}$ & Koranpergerakan & $\begin{array}{l}\text { Bisnis media } \\
\text { koran umum }\end{array}$ & $\begin{array}{l}\text { Bisnis media } \\
\text { murni }\end{array}$ & $\begin{array}{l}\text { Koran } \\
\text { perjuangan }\end{array}$ \\
\hline $\begin{array}{l}\text { Sejarah } \\
\text { kelahiran }\end{array}$ & $\begin{array}{l}\text { Berawal dari koran } \\
\text { perjuangan saat } \\
\text { revolusi bersenjata } \\
\text { tahun } 1948 \text { dengan } \\
\text { nama Harian Suara } \\
\text { Indonesia, kemudian } \\
\text { tahun } 1966 \text { menjadi } \\
\text { Harian Suluh Indonesia, } \\
\text { kemudian pada } 1 \text { juni } \\
1966 \text { menjadi Harian } \\
\text { Suluh Marhaen dan } \\
\text { pada tahun } 1972 \\
\text { menjadi Bali Post }\end{array}$ & $\begin{array}{l}\text { Media bisnis } \\
\text { murni sebagai } \\
\text { bagian dari } \\
\text { jaringan bisnis } \\
\text { koran nasional } \\
\text { yaitu Bisnis } \\
\text { Indonesia }\end{array}$ & $\begin{array}{l}\text { Bisnis media } \\
\text { yang dimiliki } \\
\text { oleh The Chung } \\
\text { Shen dan Mega } \\
\text { Endah dengan } \\
\text { nama Djava } \\
\text { Post pada tahun } \\
\text { 1949. Kemudian } \\
\text { pada tahun } 2001 \\
\text { melebarkan sayap } \\
\text { ke } 15 \text { radar, salah } \\
\text { satunya Radar } \\
\text { Bali }\end{array}$ & $\begin{array}{l}\text { Diawali } \\
\text { sebagai media } \\
\text { perjuangan } \\
\text { yang adaptif } \\
\text { dengan } \\
\text { berbagai rezim }\end{array}$ \\
\hline
\end{tabular}

Sumber: Hasil penelitian (2014)

Rubrik tersebut berjudul BaliOrti yang merupakan mimbar Bahasa Bali terletak di halaman tengah. Rubrik ini dibagi menjadi empat halaman, yaitu halaman utama, upacara, sastra dan kruna, yang semuanya ditulis dalam bahasa Bali. Di dalam rubrik kruna ada kolom berjudul Ceraken. Seperti halnya masyarakat Jawa, masyarakat Bali pun juga mengenal aksara Bali. Rubrik BaliOrti dalam harian Bali Post ini menjadi menarik karena mempunyai rubrik khusus berbahasa Bali yang sudah jarang ditemukan lagi di beberapa koran lokal lainnya.

Harian Bali Post sebagai media raksasa di Pulau Dewata, memang sangat kental dengan kebaliannya. Banyak rubrik yang mengulas Budaya Bali, baik itu dari upacara, kesenian dan identitas Bali lainnya. Akan tetapi, seiring dengan reformasi, nuansa politik terasa sangat kentara dan menjadi ulasan menarik bagi media-media lokal ,tak terkecuali harian Bali Post. Hal ini menyebabkan porsi budaya Bali dalam rubrik Bali Post menjadi berkurang.

Ajeg Bali merupakan jargon yang sering diwacanakan oleh Bali Post. Dapat dilihat dari salah satu headline koran ini
"Jadikan Bali Ajeg." Bahkan, pada 2004, Bali Post menerbitkan buku berjudul "Ajeg Bali Sebuah Cita-cita" berisikan kumpulan tulisan yang diterbitkan di koran tersebut.

Komodifikasi budaya juga terlihat pada promosi iklan Bali Post "Bali Post menjaga, mengakarkan, memperluas bisnis nasional Anda di pasar global dari Bali langgeng dan maju berdasarkan Tri Hita Karana, harmoni, seimbang, tidak merusak alam, manusia, budaya dan jati diri bangsa Indonesia" Diakui oleh budayawan dan akademisi di Bali bahwa Bali Post sering memfasilitasi diskusi bersama para pakar untuk membahas permasalahan yang sedang dihadapi Bali.

\section{(2) Terpaan (eksposure) dan Komodifikasi Harian Radar Bali}

Harian RadarBalisebagai anak media Jawa Pos, cukup diminati pembacanya, terutama dari kalangan anak muda. Radar Bali cukup aktif membangun interaksi dengan pembacanya. Pola pemberitaannya selalu disesuaikan dengan selera pasar. Rubrik berjudul Hiburan pernah mendapatkan kritik dari 
pembacanya yang kemudian oleh redaksi Radar Bali diubah menjadi Hiburan \& Budaya. Dalam perkembangannya, rubrik tersebut banyak mengulas tentang budaya kontemporer.

Jawa Pos pada tahun 2011 mendapat penghargaan Newspaper of the Year oleh World Young Reader Prize di Wina, Austria. Penghargaan itu diperoleh Jawa Pos karena keberhasilannya dalam menarik pembaca di kalangan anak muda. Dengan menyasar pembaca anak muda inilah yang kemudian juga diadopsi oleh anak-anak medianya termasuk Radar Bali.

Jika dibandingkan, porsi ulasan budaya kontemporer memang lebih mendominasi dibandingkan dengan budaya lokalnya. Namun sepertinya redaktur Radar Bali mulai melihat perspektif lain dengan melahirkan rubrikasi khusus budaya lokal Bali yang terbit satu halaman penuh setiap hari Rabu, yang diberi nama Kelir. Rubrik tersebut mengupas nilai-nilai lokal budaya Bali seperti upacara, penanggalan Bali dan lain sebagainya.

\section{(3) Terpaan (Eksposure) dan Komodifikasi Harian Solopos}

Harian Solopos secara eksplisit oleh Danie H. Soe'oed (Pimpinan Redaksi Solopos)"Budaya lokal diberi ruang secukupnya karena Solopos bukan koran budaya, tetapi koran umum". Pernyataan ini seiring dengan keinginan pemilik Solopos yang merupakan bagian dari konglomerasi media nasional yaitu media Bisnis Indonesia.

Intervensi yang paling besar dalam pemberitaan adalah dalam rapat redaksi. Forum rapat redaksi yang terdiri atas para profesional media punya otoritas yang kuat dalam melahirkan produk media. Namun demikian, idealisme para pendiri koran lokal Solopos yang kebanyakan adalah para konglomerat yang berasal dari Solo ini tidak begitu saja dapat melepaskan diri dari kedekatan nilainilai lokal sehingga proses komodifikasi yang dibangun pada akhirnya juga "memanfaatkan" nilai-nilai budaya Jawa. Proses komodifikasi isi media yang ditangani secara profesional, standar dan independen tersebut dalam tampilan isinya tampak jelas menggunakan kandungan nilai-nilai lokal sebagai penunjang yang dapat memperkaya isi dan menjadi daya tarik tersendiri.

Upaya membangun penamaan dalam rubrikasi, penokohan maupun pemberitaan dengan istilah lokal Jawa dilakukan secara intens oleh Solopos seperti rubrik $A h$ Tenane yang tampil di halaman pertama dengan menggunakan nama-nama tokoh lokal Jawa disisipi nama asing (seperti Jon Koplo atau Gendhuk Nicole), atau rubrik Lincak, yang selalu menampilkan dialog dan setting yang penuh nuansa daerah di Jawa dan pemberian nama rubrik lainnya yang sarat dengan bahasa Jawa (Ngudarasa, Nuwun Sewu, Dhasaran, Lelakon, Klangenan dan lain-lain).

Meskipun secara eksplisit koran Solopos tidak memprioritaskan terpaan/ eksposure terhadap nilai-nilai budaya Jawa secara berlebihan karena dirinya merasa sebagai koran umum, namun dalam praktik pemberitaan justru sentuhan lokal banyak yang dielaborasi untuk kepentingan bisnisnya. Praktikpraktik jurnalismenya tidak lepas dari jargon-jargon nilai budaya Jawa yang dikemas dalam ragam bahasa Indonesia (EYD) sehingga secara normatif tidak begitu kentara elaborasi bahasa Jawanya. Bahkan pada awal tahun 2007 Solopos juga turut memberikan ruang bahasa Jawa dengan menggandeng Pemerintah Jawa Tengah sebagai penyandang dana.

Proses komodifikasi yang bermodalkan pada realitas ataupun peristiwa yang senantiasa punya nilai budaya lokal tersebut menjadi modal penting dalam bangunan interaksi antara Solopos dengan pembacanya. Pelabelan sebagai koran umum dalam tatanan praktiknya tidak bisa dilepaskan dengan kondisi lokal yang ternyata punya daya tarik tersendiri, dimana Solo sebagai pusat budaya Jawa ternyata kaya akan realitas budaya yang dapat dijadikan sebagai realitas media yang layak dibaca dan bernilai ekonomis (Widodo, 2014).

\section{(4) Terpaan (Eksposure) dan Komodifikasi Harian Kedaulatan Rakyat}

Kedaulatan Rakyat sebagai koran lokal secara penuh kepemilikannya dimiliki oleh para pendirinya yang orang lokal dan tidak diintervensi oleh pemodal global tampak lebih terbuka dalam 
Tabel 2

Analisis Perbandingan Media Cetak di Bali dan Surakarta

\begin{tabular}{|c|c|c|c|c|}
\hline \multirow[b]{2}{*}{ Kriteria } & \multicolumn{2}{|c|}{ Media Lokal } & \multicolumn{2}{|c|}{ Media Regional -Nasional } \\
\hline & Bali Post & Solopos & $\begin{array}{l}\text { Radar Bali } \\
\text { (Jawa Pos) }\end{array}$ & Kedaulatan rakyat \\
\hline $\begin{array}{l}\text { Jenis } \\
\text { media }\end{array}$ & $\begin{array}{l}\text { Induk media dari } \\
\text { Harian Denpasar } \\
\text { Post, Bisnis Bali, Bali } \\
\text { TV dll. }\end{array}$ & $\begin{array}{l}\text { Anak media dari } \\
\text { Bisnis Indonesia }\end{array}$ & $\begin{array}{l}\text { Anak media dari } \\
\text { Harian Jawa Pos }\end{array}$ & Media mandiri \\
\hline $\begin{array}{l}\text { Rubrikasi } \\
\text { Budaya } \\
\text { Khusus }\end{array}$ & $\begin{array}{l}\text { BaliOrti, Kruna, } \\
\text { Isin Gumi , dll terbit } \\
\text { setiap hari minggu. }\end{array}$ & $\begin{array}{l}\text { Ah Tenane, } \\
\text { Ngudarasa, } \\
\text { Nuwun Sewu, } \\
\text { Dhasaran, } \\
\text { Lelakon, } \\
\text { Klangenan dan } \\
\text { lain-lain. } \\
\end{array}$ & $\begin{array}{l}\text { Kelir, terbit setiap } \\
\text { hari rabu. Pada } \\
\text { halaman Hiburan\& } \\
\text { Budaya diberikan } \\
\text { space khusus } \\
\text { liputan budaya. }\end{array}$ & $\begin{array}{l}\text { Penanggalan, Way- } \\
\text { angdan Dhalang, } \\
\text { Glenyengan, Rembug } \\
\text { Kota dan lain-lain. }\end{array}$ \\
\hline $\begin{array}{l}\text { Bahasa } \\
\text { Rubrik } \\
\text { Budaya }\end{array}$ & $\begin{array}{l}\text { Intens berbahasa } \\
\text { Bali }\end{array}$ & $\begin{array}{l}\text { Hanya nama } \\
\text { rubrikasi yang } \\
\text { intens memakai } \\
\text { bahasa Jawa }\end{array}$ & $\begin{array}{l}\text { Hanya nama } \\
\text { rubrikasi yang } \\
\text { intens memakai } \\
\text { bahasa Bali } \\
\end{array}$ & $\begin{array}{l}\text { Intens berbahasa } \\
\text { Jawa }\end{array}$ \\
\hline $\begin{array}{l}\text { Pemberi- } \\
\text { taan }\end{array}$ & $\begin{array}{l}\text { Sering memakai } \\
\text { nilai lokal Budaya } \\
\text { Bali seperti Tri Hita } \\
\text { Karana, dan Ajeg } \\
\text { Bali }\end{array}$ & $\begin{array}{l}\text { Isi berita } \\
\text { nampak jelas } \\
\text { menggunakan } \\
\text { kandungan nilai } \\
\text { lokal budaya Jawa }\end{array}$ & $\begin{array}{l}\text { Meski banyak } \\
\text { mengangkat } \\
\text { budaya } \\
\text { kontemporer tapi } \\
\text { tetap memakai nilai } \\
\text { lokal Bali } \\
\end{array}$ & $\begin{array}{l}\text { Tidak terjebak pada } \\
\text { isu-isu global tetapi } \\
\text { lebih menggali nilai- } \\
\text { nilai lokal Budaya } \\
\text { Jawa }\end{array}$ \\
\hline $\begin{array}{l}\text { Pertim- } \\
\text { bangan } \\
\text { Rubrikasi }\end{array}$ & $\begin{array}{l}\text { Berdasarkan } \\
\text { kepentingan dari } \\
\text { kajian team redaksi }\end{array}$ & $\begin{array}{l}\text { Berdasarkan } \\
\text { kepentingan dari } \\
\text { kajian tim redaksi }\end{array}$ & \begin{tabular}{|l} 
Pemberitaan \\
menyesuaikan \\
selera pasar agar \\
oplah meningkat. \\
\end{tabular} & $\begin{array}{l}\text { Respon pembaca dan } \\
\text { pengembangan nilai- } \\
\text { nilai lokal }\end{array}$ \\
\hline $\begin{array}{l}\text { Komodifi- } \\
\text { kasi }\end{array}$ & $\begin{array}{l}\text { Rubrik dan Opini } \\
\text { Budaya Bali } \\
\text { Pemberitaan sarat } \\
\text { nilai-nilai Budaya } \\
\text { Bali. } \\
\text { Penanggalan Bali } \\
\text { Lembar Bahasa Bali } \\
\text { Jargon Bali }\end{array}$ & $\begin{array}{l}\text { Labeling rubrik- } \\
\text { rubrik yang } \\
\text { bernuansa lokal } \\
\text { (Urun Rembuk, } \\
\text { Lincak, Ah Tenane } \\
\text { dII) } \\
\text { Khusus nilai-nilai } \\
\text { lokal (Gunungan, } \\
\text { Wayang, Ritual } \\
\text { dlI) }\end{array}$ & $\begin{array}{l}\text { Rubrik khusus } \\
\text { Budaya Bali dan } \\
\text { Labeling bernuansa } \\
\text { lokal seperti rubrik } \\
\text { Kelir } \\
\text { Penanggalan Bali }\end{array}$ & $\begin{array}{l}\text { Rubrik dan Opini } \\
\text { Budaya Jawa } \\
\text { Pemberitaan sarat } \\
\text { nilai-nilai Budaya } \\
\text { Jawa. } \\
\text { Penanggalan Jawa } \\
\text { Lembar Bahasa Jawa }\end{array}$ \\
\hline
\end{tabular}

Sumber: Analisis Data (2014)

memberikan porsi terpaan terhadap nilai-nilai budaya Jawa. Kedaulatan Rakyat tidak terjebak pada isu-isu global tetapi malahan lebih menggali nilainilai lokal budaya Jawa dan kepedulian tersebut diolah secara kreatif menjadi komoditas yang tidak kalah menariknya dibandingkan dengan produk global. Dari sisi penamaan rubrik banyak ditemukan unsur-unsur lokal bahasa Jawa seperti rubrik Penanggalan, Wayangdan Dhalang, Glenyengan, Rembug Kota dan lain-lain. Sedangkan dalam pemilihan dan penyajian realitas secara eksplisit terhadap berbagai fenomena yang terkait dengan nilai-nilai budaya Jawa dapat menjadi daya tarik tersendiri sehingga dinamika budaya masyarakatnya secara simultan hadir di medianya sebagai berita yang marketable. Bahkan, selama seminggu sekali Kedaulatan Rakyat masih menampilkan rubrik Mekarsari yang ditulis dengan bahasa Jawa sebanyak satu halaman penuh. Representasi isi dengan mengunakan bahasa Jawa dalam realitas bisnis koran lokal dinilai menguntungkan bagi keberjalanan media lokal.

Proses komodifikasi berita yang mengacu pada proses transformasi nilai guna yang didasarkan pada kepemimpinan generasi penerusnya dalam memenuhi kebutuhan terhadap suatu nilai tukar yang 
berdasarkan pada kepentingan pasar menjadi proses dialektik yang sangat dipengaruhi oleh nilai-nilai Jawa. Oleh Octo Lampito (Pimpinan Redaksi KR) koran KR sebagai community newspaper menjadikan budaya Jawa sebagai basic gerak langkah organisasi. Namun demikian, ia tetap mengedepankan doktrin yang senantiasa mengikuti perkembangan zaman sehingga dalam level individual peran para profesional media dituntut profesional dalam pengembangan kerja jurnalistiknya.

Proses komodifikasi isi yang senantiasa mengubah pesan dari sekumpulan data ke dalam sistem makna yang layak jual diwujudkan dengan tampilan-tampilan isi yang tidak mendoktrin atau menggurui pembacanya, sehingga harmonisasi hubungan masyarakat dengan media menjadi setara. Di samping itu, isi yang dikemas juga merupakan pikiran-pikiran baru yang inovatif ataupun berupa analisis-analisis yang tidak keluar dari jurnalistik yang berkultur Jawa.

Dalam terminologi komodifikasi, ternyata koran lokal KR ini juga mampu menghasilkan sebuah proses yang memungkinkan dirinya menyajikan sejumlah informasi budaya kepada konsumen. Proses komodifikasi isi dan komodifikasi khalayak berjalan paralel seperti yang digambarkan oleh Octo Lampito bahwa KR menjadi media peneguh budaya Jawa, sehingga dalam terminologi bisnisnya tergambarkan bahwa iklan di KR itu bukan sekadar iklan semata tetapi dapat dipandang sebagai informasi yang pantas dibaca. Kerjasama bidang iklan dan pemberitaan menjadi keunikan tersendiri meskipun secara manajerial manajemen yang dipakai pemiliknya (owner) adalah manajemen keluarga. Pemakaian bahasa yang sarat dengan jargon-jargon maupun idiom-idiom Jawa tidak menjadikan bahasanya menjadi sulit dimengerti oleh para pembaca dari luar daerah.

Proses komodifikasi dengan menggali nilai-nilai budaya Jawa, terutama dalam penyajian hal-hal yang bersifat mistik, pernah pula didebat karena dinilai irasional, sehingga saat ini kupasan tentang informasi/ pemberitaan yang berbau mistik disajikan secara lebih rasional. Bahkan, dalam pemilihan para wartawan untuk liputan-liputan tertentu yang sarat dengan nilai-nilai budaya Jawa perlu mempertimbangkan spesialisasi agar pemberitaannya dapat lebih mengena dan sesuai dengan makna simbolik yang terkandung di dalamnya (Widodo, 2014).

\section{Simpulan dan Saran}

Berdasarkan kajian di atas penelitian ini menyimpulkan bahwa proses komodifikasi budaya telah terjadi, baik pada media lokal maupun media nasional. Proses tersebut terjadi baik di Bali dan juga di Solo. Budaya masih memiliki kerapuhan untuk menghindari diri dari aksentuasi kapitalisme di dalam industri media sehingga pemahaman dan konstruksi budaya dapat di arahkan kepada kepentingan bisnis.

Media massa tidak memroduksi atau mereproduksi identitas budaya, tetapi melakukan komodifikasi untuk kepentingan keberlanjutan dan peningkatan bisnis media. Maka dari itu, penulis merekomendasikan kepada para pelaku bisnis media, khususnya media lokal, untuk menjaga dan melestarikan kebudayaan lokal secara faktual berdasarkan nilai-nilai luhur, bukan sekadar aktual atau sebatas simbol-simbol kebudayaan saja. Hal ini menjadi penting bagi kontribusi media terhadap identitas bangsa dan bukan hanya tentang hitungan keuntungan semata.

\section{Daftar Pustaka}

Adam, Ahmad. (2003). Sejarah Awal Pers dan Kebangkitan Kesadaran Keindonesiaan. Jakarta: Hasta Mitra.

Albaran, Alan B. (1996). Media Economics, Understanding Markets, Industries and Concepts. Ames, Iowa: Iowa State University Press.

Anwar, Rosihan. (2006). "Wartawan Engkau Pahlawan Dalam Hatiku." Jakarta: Pidato Pengukuhan DR (HC), Universitas Islam Negeri (UIN) Syarif Hidayatullah, Sabtu 6 Mei 2006.

Balaga, Sonja. (2005). "Pembelajaran Pedalangan: Mencari Jiwa Wayang. Yogyakarta:" Laporan Studi Lapangan di Yogyakarta.

Brandon, James. (1970). On Thrones of Gold. Cambridge: Harvard University Press.

Bungin, Burhan. (2010). Analisis Data Penelitian Kualitatif.Jakarta: PT. Raja Grafindo Persada.

Chaerowati, Dede Lilis, et.al. (2013). "Mengusung Masyarakat Madani melalui Radio Komunikasi." Bandung: Mimbar Jurnal Sosial dan Pembangunan, Unisba, Vol 29 No 2, pp 145-154.

Deliarnov. (2006). Ekonomi Politik. Jakarta: Erlangga.

Eriyanto. (2002). Analisis Framing; Konstruksi, Idiologi dan Politik Media. Yogyakarta: LKiS. 
Giddens, Anthony. (1984). The Constitution of Society: Outline of the Theory of Strukturation. Cambridge: Polity Press.

Giddens, Anthony. (2001). Runaway World: Bagaimana Globalisasi Merombak Kehidupan Kita. Jakarta: Gramedia Pustaka Utama.

Hamad, Ibnu. (2002). "Media Massa dan Konstruksi Realitas Politik. "Jurnal Penelitian IImu Komunikasi, Vol. III/ No.1 Januari-April 2004.

Hamad, Ibnu. (2004). Konstruksi Realitas Politik dalam Media Massa. Jakarta: Granit.

Hardjowirogo, Marbangun. (1983). Manusia Jawa. Jakarta: Yayasan Idayu.

Hidayat, Dedy N, et.al. (2000). Pers dalam Revolusi Mei, Runtuhnya Sebuah Hegemoni. Jakarta: Gramedia Pustaka Utama.

Kellner, Douglas. (2002). "Theorizing Globalization."Sociological Theory, Vol 20, Issue 3, pp 285-305.

Lippman, Walter. (1998). Pendapat Umum. Jakarta: Yayasan Obor Indonesia..

Littlejohn, Stephen W. (1999). Theories of Human Communication. Belmont CA: Wadsworth Publishing Company.

Lukmantoro, Triyono. (2002). " RUU Penyiaran dan Budaya Lokal."Suara Merdeka, 14 September.

McQuail, Denis. (1991). Teori Komunikasi Massa. Jakarta: Erlangga.

McQuail, Denis. (2000). McQuil's Mass Communication Theory. London: Sage Publications.

Milles and Huberman. (1992). Analisis Data Kualitatif. Jakarta: Universitas Indonesia Press.

Mosco, Vincent. (1996). The Political Economy of Communication, Rethingking and Renewal. London: Sage Publications.
Muktiyo, Widodo. (2014). Dinamika Media Lokal dalam Mengkonstruksi Realitas Budaya Lokal sebagai Sebuah Komoditas. Surakarta: Universitas Sebelas Maret Press.

Muhadjir, Noeng. (2000). Metodologi Penelitian Kualitatif. Yogyakarta: Reka Sarasin.

Neuman, W Lawrence. (1997). Social Research Methods Qualitative and Quantitative Approaches, $3^{\text {rd }}$, Boston, Altin dan Bacon.

Oetama, Jacob. (2001). Pers Indonesia Berkomunikasi dalam Masyarakat Tidak Tulus. Jakarta: Penerbit Buku Kompas.

Pawito. (2013). "Konstruksi Identitas Kultural Masyarakat pluralis dalam Terpaan Globalisasi." Bandung: Mimbar, Jurnal Sosial dan Pembangunan, Unisba, Vol. 29 No 1.

Poerwadarminta. (1985).Kamus Umum Bahasa Indonesia. Jakarta: Balai Pustaka.

Ritzer, George dan Goodman. (2003). Teori Sosiologi Modern. Jakarta: Kencana.

Sen, Krishna dan David T. Hill. (2001). Media, Budaya dan Politik Indonesia. Jakarta: ISAI.

Shoemaker, Pamela J. and Stephen D. Reese. (1996). Mediating The Message: Theories of Influences on Mass Media Content. Second edition. New York: Longman.

Smythe, Dallas. (1977). Communication: Blindspot of Western Marxism. Canadian Journal of Political and Social Theory, Vol 1 number 3 .

Stiglitz, Joseph E. (2002). Globalization and its Discontents. New York \& London: WW. Norton.

Swartz, David. (1997). Culture and Power: The Sociology of Pierre Bourdieu. Chicago: The University of Chicago Press.

Triputra, Pinckey. (2004)."Dilema Industri Penyiaran di Indonesia." Disertasi. UI Depok. 